\title{
ПРОБЛЕМЫ СТРОИТЕЛЬНОЙ ОТРАСЛИ В ПЕРИОД ПАНДЕМИИ КОРОНАВИРУСА И ПРАВОВЫЕ РЕШЕНИЯ ГОСУДАРСТВА ПО ПОДДЕРЖКЕ ЗАСТРОЙЩИКОВ
}

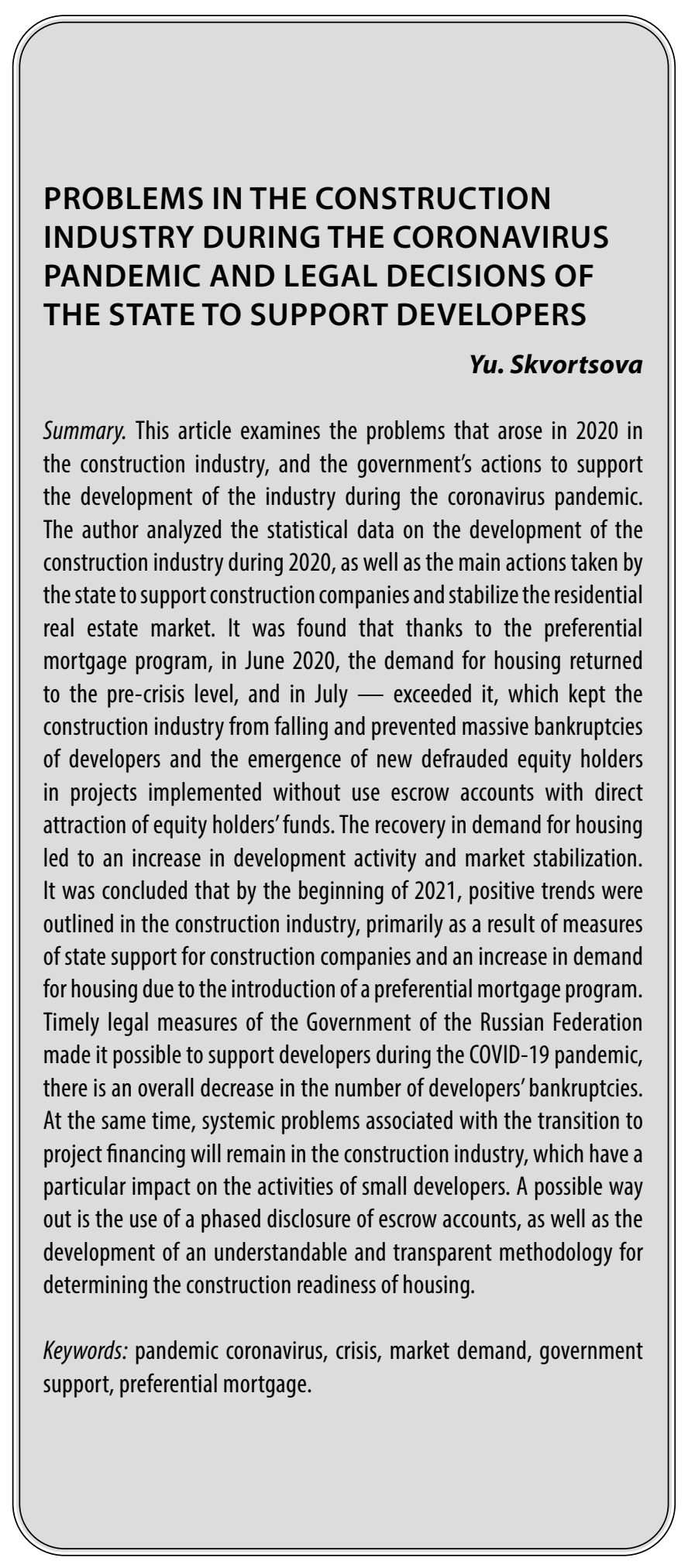

Сквориова Юлия Сергеевна

Старший преподаватель кафедры Гражданского права, Средне-Волжский институт (филиал) Всероссийский государственный университет юстиции (РПА Минюста России), город Саранск juliyav777tt@mail.ru

Аннотация. Рассмотрены проблемы, возникшие в 2020 году в строительной отрасли, и действия государства по поддержке развития отрасли в период пандемии коронавируса. Автором проведен анализ статистических данных развития строительной отрасли в течение 2020 года, а также предпринятых основных действий со стороны государства по поддержке строительных предприятий и стабилизации рынка жилой недвижимости. Установлено, что благодаря программе льготной ипотеки уже в июне 2020 года спрос на жилье вернулся к докризисному уровню, а в июле — превысил его, что удержало строительную отрасль от падения и позволило предотвратить массовые банкротства застройщиков и возникновение новых обманутых дольщиков в проектах, реализуемых без использования счетов эскроу с прямым привлечением средств дольщиков. Восстановление спроса на жилье привело к увеличению девелоперской активности и стабилизации рынка. Сделан вывод, что к началу 2021 года В строительной отрасли наметились положительные тенденции, прежде всего, в результате действия мер государственной поддержки строительных компаний и повышения спроса на жилье за счет введения программы льготной ипотеки. Своевременные правовые меры Правительства РФ позволили поддержать застройщиков в период пандемии COVID-19. 0тмечается общее снижение числа банкротств застройщиков. Вместе с тем, в строительной отрасли сохранятся системные проблемы, связанные спереходом на проектное финансирование, оказывающие особое влияние на деятельность небольших застройщиков. Возможным выходом выглядит применение поэтапного раскрытия эскроу-счетов, а также разработка понятной и прозрачной методики определения строительной готовности жилья.

Ключевые слова: пандемия коронавируса, кризис, рыночный спрос, поддержка государства, льготная ипотека. 


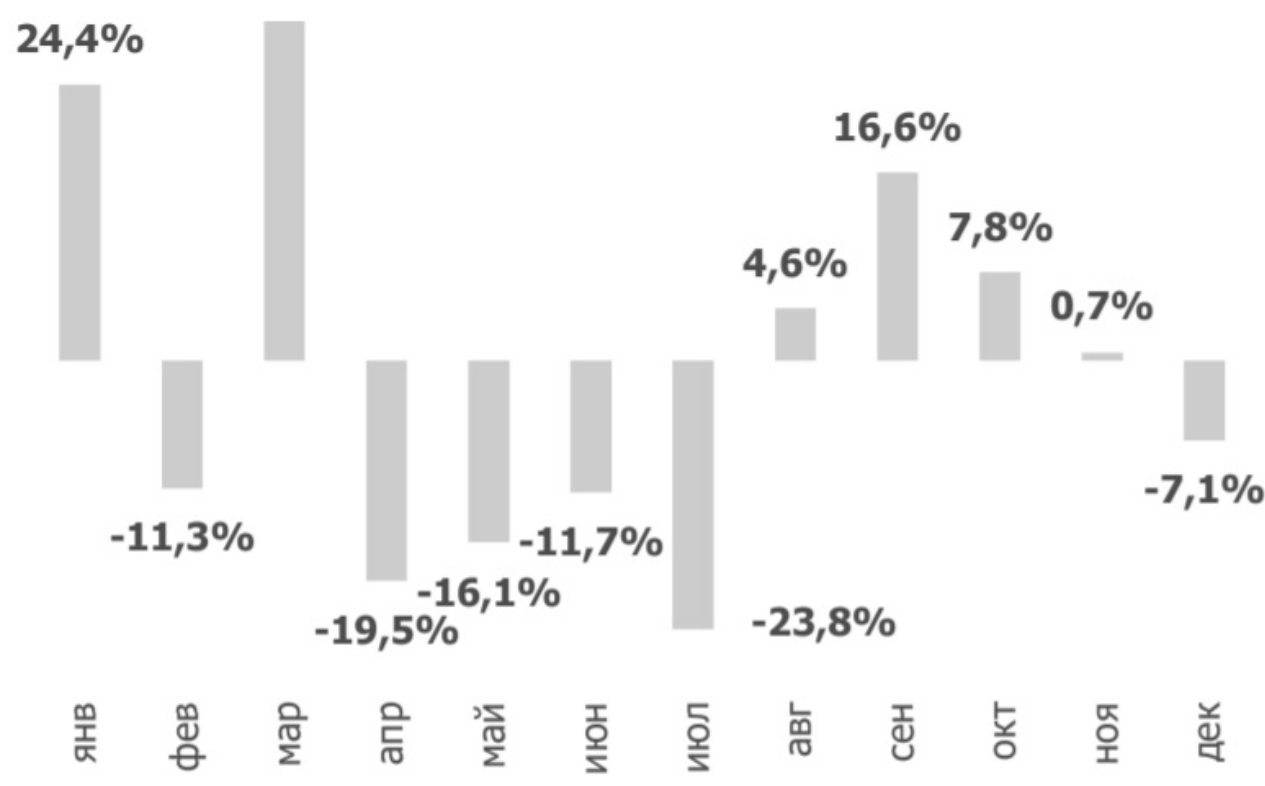

Рис. 1. Динамика ввода МКД в 2020 году помесячно к декабрю 2019 года,\% (по данным Росстата, расчеты ДОМ.РФ) [4]

\section{$\begin{array}{lllllllllll}\mathbf{1}, 2 & +5 & +20 & \mathbf{- 1 7} & \mathbf{- 0 , 4} & +21 & +45+45+86 & +79+62+46\end{array}$}

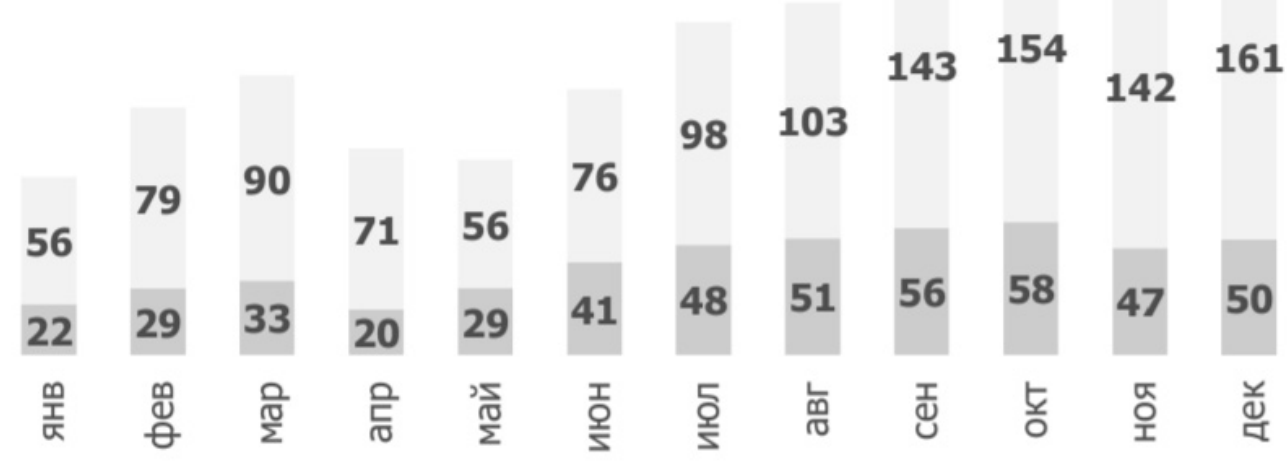

- Первичный рынок В Воричный рынок $\quad$ XX Прирост г/г, \%

Рис. 2. Динамика выдачи ипотечных кредитов по сегментам в 2020 году, тыс. шт. (по данным Банка России, расчеты ДОМ.РФ) [4]

троительство, выступая неотъемлемой составляющей национальной экономики, во многом определяет социально-экономическое развитие страны. Так, по данным Росстата в 2019 году предприятия строительной отрасли выполнили работ на сумму более 9,13 трлн. руб., что составило 5,6\% от ВВП страны. В стадии строительства находилось около 77,8 тыс. объектов разного назначения, строительство которых обеспечивало 93,1 тыс. подрядных организаций членов саморегулируемых организаций (СРО) и 3340 


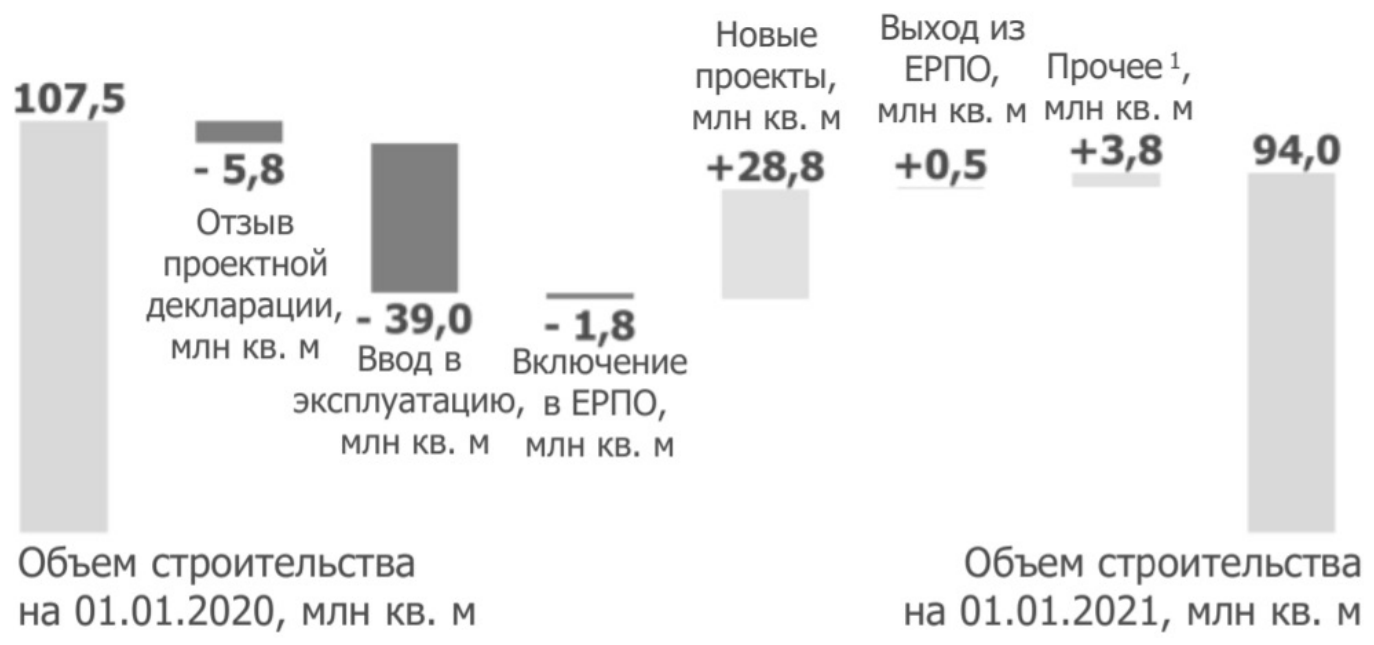

Сокращение: ЕРПО - Единый реестр проблемных объектов

Рис. 3. Баланс объемов строительства МКД за 2020 год (по данным ЕИСЖС, расчеты ДОМ.РФ) [4]

компаний - застройщиков жилья. При этом около 90\% строительных компаний являлись малыми и средними предприятиями. В строительной отрасли на конец 2019 года было трудоустроено более 6 млн. граждан России [1]. Поэтому ситуация в строительной отрасли оказывает мультипликативный эффект на развитие других отраслей и экономии России в целом.

Как отмечали специалисты Центра конъюнктурных исследований ВШЭ [2], уже в течение уже 1-го квартала 2020 года было нивелировано большинство позитивных составляющих, достигнутых в сфере строительства за последние годы. Проведенный опрос топ-менеджеров и собственников строительных компаний показал, что каждый второй из них (48\% респондентов) отмечал спрос ниже нормального уровня. 30\% опрошенных указывали на сокращение числа заключенных договоров, более трети респондентов отмечали снижение объемов выполняемых работ, еще 30\% назвали главным фактором, ограничивающим деятельность строительных компаний, недостаток заказов. До 30\% выросла доля компаний, вынужденных сокращать персонал, ввиду ухудшения финансового состояния строительных предприятий. Как отмечали специалисты ВШЭ, для строительного сектора были свойственны преимущественно негативные настроения и кризис доверия.

Для поддержки застройщиков со стороны государства был принят ряд решений, которые предполагали временное смягчение норм действующего законодательства к застройщикам. В частности, антикризисные меры касались ситуаций, в котороых нарушается срок передачи объекта долевого строительства, а также сроки завершения строительства и процедуры банкротства [3]. Данные изменения учитывали ситуацию, в которой оказались добросовестные застройщики в условиях пандемии, и позволяли снизить финансовую нагрузку в период до 1 января 2021 года как на застройщиков, так и на участников долевого строительства.

Необходимо признать, что принятие мер со стороны государства в течение марта-мая 2020 года (снятие локдауна и ограничений при проведении строительных работ, финансовые и налоговые меры поддержки субъектов рынка, введение программы льготной ипотеки для объектов жилищного строительства и др.) позволило частично снизить напряженность на строительном рынке и дальнейшее развитие негативных тенденций.

В результате действия негативных макроэкономических факторов в течение 2020 года отмечалась динамика снижения ввода многоквартирных домов (далее МКД) (см. Рисунок 1).

Как показывает анализ представленных данных, с апреля по июль 2020 года отмечалось значительное падение количества введенных в строй новых МКД. Осенью ситуация была улучшена, но в декабре опять было отмечено падение показателя относительно уровня декабря 2019 года.

Во многом рынок поддержало введение программы льготной ипотеки, что позволило повысить спрос на жилую недвижимость (см. Рисунок 2).

Анализ представленных данных показывает, что с июня 2020 года отмечается значительный прирост выдачи ипотечных кредитов на первичном рынке. Стабилизации ситуации в жилищном строительстве способствовало повышение доступности рыночных 
ипотечных кредитов, а также реализация комплекса мер поддержки строительной отрасли, принятых по поручению Президента России, среди которых наиболее действенной стала программа льготной ипотеки под 6,5\%. Благодаря данной программе уже в июне 2020 года спрос на ипотеку и жилье вернулся к докризисному уровню, а в июле - превысил его, что удержало строительную отрасль от падения и позволило предотвратить массовые банкротства застройщиков и возникновение новых обманутых дольщиков в проектах, реализуемых без использования счетов эскроу с прямым привлечением средств дольщиков.

Вместе с тем, несмотря на то, что во 2-м полугодии 2020 года активно росли запуски новых строительных проектов, их отставание от объема вводимого жилья обусловило снижение объема строящегося жилья.

Так, по состоянию на 1 января 2021 года объем многоквартирного жилья в стадии строительства в России составлял 94 млн. м², сократившись за год на 12,5\% или 13,5 млн. м², что было связано с недостатком запусков новых проектов в 1-м полугодии на фоне пандемии коронавируса и падения спроса на жилье. Приведенные данные по объему строящегося жилья основаны на информации Единой информационной системы жилищного строительства (далее - ЕИСЖС) и не учитывают строительство МКД, возводимого без привлечения средств дольщиков (см. Рисунок 3).

Своевременные меры государственной поддержки обеспечили рост количества зарегистрированных договоров долевого участия (далее - ДДУ) во 2-м полугодии 2020 года на 64\% в сравнении с сопоставимым периодом 2019 года. В результате на 1 января 2021 года оказалось продано 66\% строящегося жилья с заявленным сроком ввода в 2021 году.

Восстановление спроса на жилье привело к увеличению девелоперской активности - с августа по декабрь 2020 года объем запусков новых проектов превышал уровень аналогичного периода 2019 года на 39\%, максимальный прирост был зафиксирован в конце года, что указывает на восстановление рынка (в декабре 2020 года было запущено новых проектов на 4,7 млн. м² или 196\% к декабрю 2019 года).

Несмотря на рост запуска новых проектов во 2-м полугодии 2020 года, по итогам всего года ввод в эксплуатацию жилья более чем на треть превысил объем новых проектов. Так, за весь 2020 год в информационной системе ЕИСЖС застройщиками было размещено

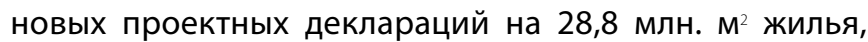
а разрешений на ввод в эксплуатацию - на 39 млн. м $^{2}$ жилья. Это стало значительно ниже целевых ориенти- ров программы «Комфортная и безопасная среда для жизни», которая предусматривала ввод 120 млн. м² жилья ежегодно.

По итогам 2020 года в Российской Федерации отмечено банкротство 162 застройщиков, возводивших 374 дома (2,4 млн. м² жилья). При этом число банкротств за год сократилось на 12\% [5]. Своевременные правовые меры Правительства РФ позволили поддержать застройщиков в период пандемии COVID-19, отмечается общее снижение числа банкротств застройщиков, но сама ситуация действия негативных макроэкономических факторов осложнила ведение бизнеса для небольших застройщиков, что сказывается на дальнейшем сокращении их числа на рынке [6].

Успешной работе компаний мешают продолжающийся рост стоимости стройматериалов, ограничение доступа к дешевой рабочей силе и опасения покупателей жилья относительно платежеспособности и устойчивости бизнеса региональных компаний.

Переход на систему проектного финансирования остается серьезной проблемой для небольших застройщиков. Начиная с 1 июля 2019 года все российские девелоперы, привлекающие средства дольщиков, должны использовать для новых проектов механизм эскроу-счетов, который предполагает, что получить деньги приобретателей жилья застройщики смогут только после передачи им квартир, а сам процесс строительства должен осуществляться на привлекаемые банковские кредиты.

Но при этом на практике застройщику крайне сложно получить кредитование, если маржа проекта составляет ниже 15\%. В этой ситуации существенно облегчить деятельность застройщиков и увеличить рентабельность проектов способно поэтапное раскрытие эскроу-счетов, когда застройщик смог бы получать некую компенсацию за уже частично освоенные средства и выполненный объем работ. Кроме этого, выглядело бы привлекательным применение более низких ставок по кредиту или рефинансирование - если застройщик выполняет работы по графику и идет постоянное наполнение счетов эскроу.

В нынешней же ситуации при проектном финансировании проценты по кредиту начисляются на весь объем постоянно растущего тела кредита. Возникает парадокс, когда застройщик накапливает долги (постоянно действуют кредитные проценты), в то время как коммерческий банк - фактически посредник между застройщиком и покупателем - аккумулирует вносимые средства на эскроу-счета и пользуется этими деньгами, которые впоследствии (по окончанию строительства) пойдут на погашение кредита застройщика. 
Считаем, что применение поэтапного раскрытия эскроу-счетов даст возможность застройщикам для проведения эффективных инвестиций, что позитивно скажется на стоимости жилья. Однако при этом данный механизм необходимо использовать так, чтобы он не стал противоречием сути проведенного ранее реформирования по исключению рисков для дольщиков. На наш взгляд, в этом случае необходимо решение ряда принципиальных проблем:

1. Разработка понятной и прозрачной методики определения строительной готовности жилья;

2. Создание четкого порядка взаимодействия коммерческих банков не только с застройщиками, но и с покупателями жилья.

На сегодняшний день согласно нормативных требований дольщик в любой момент до ввода дома в эксплуатацию имеет право расторгнуть ДДУ без объяснения причин, что создает серьезный риск потери ликвидности для застройщика. Поэтому необходимо создание механизма защиты застройщиков в виде законодательного принятия достаточных оснований для расторжения сделки, например, нарушение технологии строительства, ведущее к рискам разрушения конструкции, низкое качество выполненных работ, замена стройматериалов на более дешевые, фактическая непригодность объекта к нормальной эксплуатации и др. В этой ситуации при условии поэтапного раскрытия эскроу-счетов сами дольщики должны быть согласны с тем, что перечисление денег застройщику станет означать принятие уполномоченным банком определенной части выполненных строительных работ, что будет снижать возможности дольщиков для предъявления претензий застройщику, а значит, исключать возможность резкого снижения его платежеспособности ввиду расторжения Дду.

Кроме этого, поэтапное открытие эскроу-счетов позволит снижать цену жилья и применять различные маркетинговые стратегии по привлечению потенциальных покупателей, так как застройщик сможет стимулировать продажи на всех этапах строительства. В ситуации, когда доступ к средствам на эскроу-счетах остается закрытым, наиболее привлекательной рыночной ценовой стратегией для застройщика является начало продаж ближе к завершению строительства, когда стоимость 1 м² жилья будет приближена к максимальной. В том же случае, если девелопер сможет получать денежные средства частями, то он сможет самостоятельно регулировать цену продажи - исходя из необходимости привлечь дополнительные средства и увеличить продажи. Несомненно, что при этом цена жилья на более ранних стадиях строительства будет ниже, чем без поэтапного раскрытия, а применение различных скидок может стать лучшим стимулом для покупателя.
Следует признать, что важнейшей проблемой строительной отрасли, которая еще больше актуализировалась в год пандемии, стало изменение финансирования проектов после применения схемы эскроу-счетов. Несмотря на различные меры государственной поддержки, в данном случае требования по маржинальности новых проектов в рамках проектного финансирования так и остались высокими - на уровне 20-25\% [7]. Но такой уровень показывают далеко не все проекты застройщиков.

Считаем, что в современных условиях необходимо создать эффективную программу повышения маржинальности строительных проектов, что может быть реализовано за счет снижения дополнительной инженерной, социальной и транспортной нагрузки на девелоперов. Это предложение давно обсуждается в научной среде, но так и не стало правовым решением. Инструментом реализации подобного решения, по нашему мнению, может стать выпуск «инфраструктурных» облигаций по программе «Жилье и городская среда», а также использование механизма государственно-частного партнерства (ГЧП) при строительстве социальных объектов.

Таким образом, в течение 2020 года строительная отрасль в полной мере испытала на себе негативные последствия, вызванные пандемией коронавируса, что привело к значительному сокращению рыночного спроса на жилые и коммерческие объекты, что способствовало ухудшению доходности деятельности строительных компаний и их платежеспособности, а значит, и росту риска банкротства. Но к началу 2021 года в строительной отрасли наметились положительные тенденции, прежде всего, в результате действия мер государственной поддержки строительных компаний и повышения спроса на жилье за счет введения программы льготной ипотеки.

Своевременные правовые меры Правительства РФ позволили поддержать застройщиков в период пандемии COVID-19, отмечается общее снижение числа банкротств застройщиков. Вместе с тем, в строительной отрасли сохранятся системные проблемы, связанные с переходом на проектное финансирование, оказывающие особое влияние на деятельность небольших застройщиков. Возможным выходом выглядит применение поэтапного раскрытия эскроу-счетов, разработка понятной и прозрачной методики определения строительной готовности жилья. Это требует серьезной законотворческой работы и взаимодействия с экспертным сообществом, так как необходимо, создав лучшие условия для застройщиков, обеспечить минимизацию рисков дольщиков. 


\section{ЛИТЕРАТУРА}

1. Официальный сайт Федеральной службы государственной статистики [Электронный ресурc]. URL: https://rosstat.gov.ru.

2. Центр конъюнктурных исследований НИУ ВШЭ [Электронный ресурc]. URL: https://issek.hse.ru/dep_conres.

3. Кулыбин М. Государство нам поможет. Меры поддержки отрасли // ASNinfo.ru. Агентство строительных новостей [Электронный ресурс]. URL: https:// asninfo.ru/articles/1718-gosudarstvo-nam-pomozhet-mery-podderzhki-otrasli.

4. Обзор рынков жилья, жилищного строительства и ипотеки в 2020 году // дОМ.РФ [Электронный ресурс]. URL: https://д0м.pф/upload/iblock/e84/e847 279b9139afd0ae3f407cd6fb7bf5.pdf.

5. Мерцалова А. У регионов упала себестроимость // Коммерсантъ [Электронный ресурс]. URL: https://www.kommersant.ru/doc/4704087.

6. Лунькова В. Ключевые события рынка недвижимости 2020года //РБК [Электронный ресурc].URL:https://realty.rbc.ru/news/5fe102f99a7947b448dc2cb2.

7. Апольский П. Семь «ключей» строительной отрасли эпохи коронавируса // ASNinfo.ru. Агентство строительных новостей [Электронный ресурс]. URL: https://asninfo.ru/articles/1772-sem-klyuchey-stroitelnoy-otrasli-epokhi-koronavirusa.

(с Скворцова Юлия Сергеевна ( juliyav777tt@mail.ru ).

Журнал «Современная наука: актуальные проблемы теории и практики»

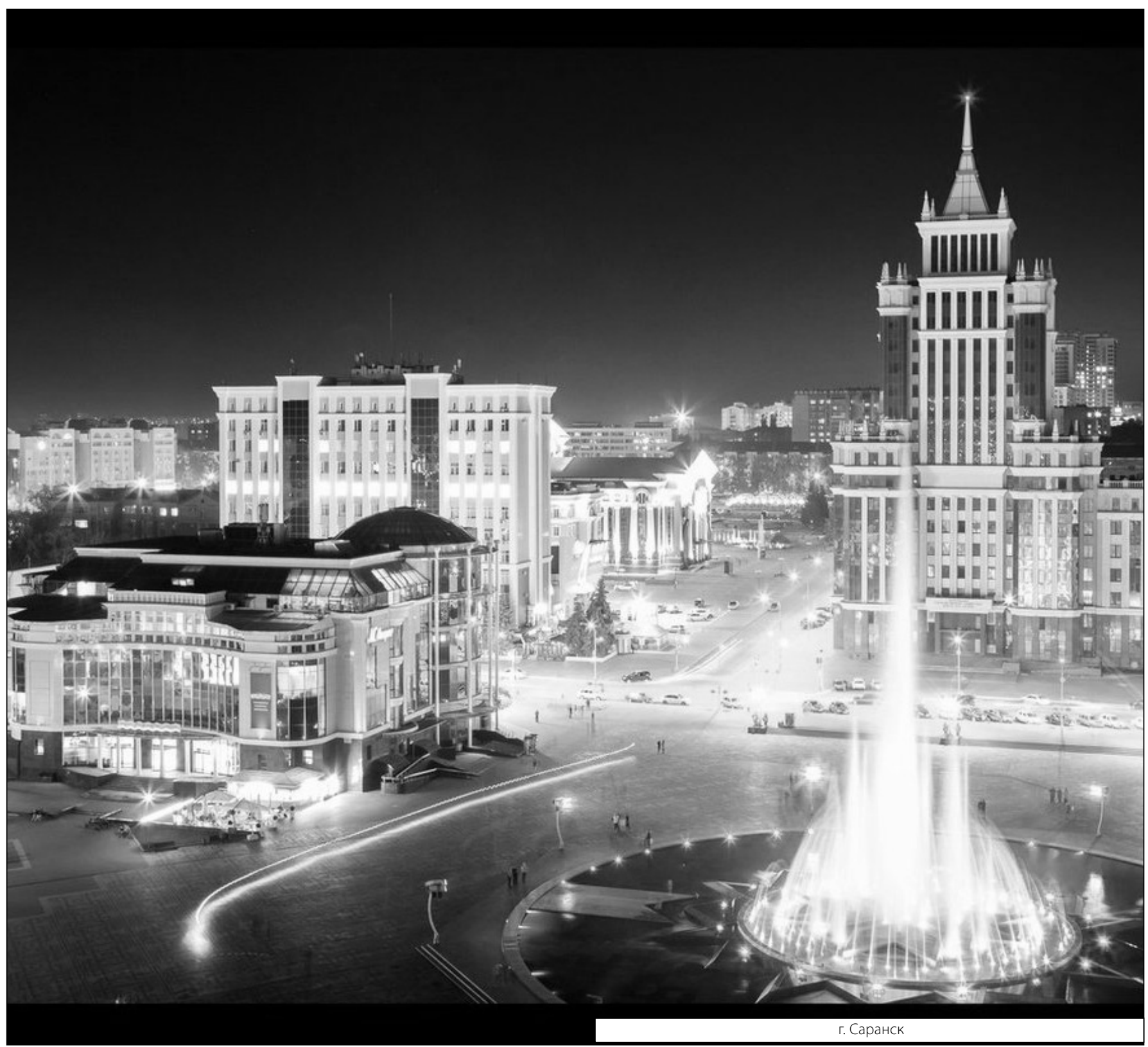

